\title{
The Effects of the MyoKinesthetic System on Medial Tibial Stress Syndrome in the Physically Active: A Case Study
}

Rodrigo E. Martinez, DAT, LAT, ATC*; Evelyn Benitez-Lopez, DAT, ATC + ; Lindsey Larkins, DAT, CSCS, PRT-C $\ddagger$

* Florida International University, Miami, FL; †East Los Angeles College, Monterey Park, CA; $\ddagger$ University of Idaho, Moscow, ID

\begin{abstract}
Medial tibial stress syndrome (MTSS) is a common pathology in physically active people and one of many overuse leg injuries present in weight bearing athletes, with the highest prevalence in runners. Researchers have extensively explored treatment for MTSS, but a long-lasting and effective treatment option has not been established. This case report aimed to explore the effects of The MyoKinesthetic System ${ }^{T M}$ (MYK), a form of manual therapy, on two athletes diagnosed with MTSS. Patient one is a 19-year-old male rugby player with a previous history of MTSS, who reported leg pain while running which progressed to constant pain. Patient two is a 24-year-old female collegiate soccer patient who reported increasing leg pain while running, with no previous history of MTSS. After being diagnosed with MTSS, both patients' posture was evaluated using the MYK postural analysis to identify and treat the primary nerve root dysfunction (i.e., S1). Each patient received a total of six MYK treatment sessions over a two-week period. Treatment included manual stimulation via tactile feedback of each muscle innervated by the primary dysfunctional nerve root. Treatments were performed bilaterally with alternating patterns of 4-10 passive and active movements. Implementation of manual therapy resulted in long-term, full resolution of symptoms without modifying or restricting athletic participation. Both patients reported a decrease in pain and an increase in function across six treatment sessions without curtailing activity. Manual therapy techniques such as MYK may be a suitable treatment option for physically active patients with MTSS. The outcomes of this case report suggest that MYK may help improve and ultimately resolve MTSS pain and dysfunction in patients involved in weight bearing physical activity. Future studies should continue to examine the effectiveness of these techniques via randomized clinical trials.
\end{abstract}

\section{Key Phrases}

Manual techniques, patient-reported outcomes, injury risk reduction

\section{Correspondence}

Dr. Rodrigo E. Martinez, Florida International University, 11200 SW 8th Street, AHC3-331, Miami, FL 33199.

E-mail: matinr@fiu.edu

\section{Full Citation}

Martinez RE, Benitez-Lopez E, Larkin L. The effects of the myokinesthetic system on medial tibial stress syndrome in the physically active: a case study. Clin Pract Athl Train. 2020;3(3):37-45.

https://doi.org/10.31622/2020/000.3.3.6.

Submitted: January 15, 2020 Accepted: April 31, 2020

\section{INTRODUCTION}

Medial tibial stress syndrome (MTSS), also known as "shin splints", is a lower extremity pathology reported during repetitive weight bearing activities such as running 1-2 and other ballistic sports such as basketball, tennis and track and field. ${ }^{3}$ Signs and symptoms include dull, aching or diffuse pain in the distal $2 / 3$ of the posteromedial tibia. ${ }^{4}$ Pain is usually absent during moments of inactivity, but will increase during physical activity, and palpation of the posteromedial tibia can elicit pain. 5 Conflicting etiologies and numerous predisposing factors make it difficult to identify a singular root cause. ${ }^{3}$ Differences in pronation, plantar flexion, hip internal and external rotation, when compared bilaterally, are examples of intrinsic risk factors contributing to the development of MTSS.3,6 Imbalances in any of the aforementioned risk factors can alter mechanics along the lower extremity kinetic chain. ${ }^{3}$ With these subtle variations in posture, a patient may develop pain and experience decreased function.

Current conservative interventions (e.g., rest, ice, massage, stretching, strengthening) used to treat MTSS address the patient's local area of pain, but none focus on reducing intrinsic risk factors, specifically those that affect posture. A suggested approach to treatment is to view the body as a whole, emphasizing the need for a global assessment, as opposed to focusing on the local 
area of pain.7-8 The MyoKinesthetic System ${ }^{\top M}$ (MYK) is a global manual therapy treatment model developed by Dr. Michael Uriarte. The treatment paradigm is designed to assess and balance the nervous system by treating the muscles innervated by specific nerve pathways. ${ }^{9}$ The purpose of MYK is to evaluate postural imbalances and treat neuromuscular dysfunction as a method to restore allostasis, or homeostasis within reasonable fluctuation.9-10 Once postural imbalances are identified, the clinician can provide a patient specific treatment to improve postural dysfunctions, while decreasing pain and restoring function. Limited evidence exists on MYK, however, previous published works include a comprehensive overview of MYK, its positive effects on low back pain, ${ }^{11}$ disc herniations, ${ }^{12}$ chronic knee osteoarthritis, ${ }^{13}$ and MTSS. ${ }^{14}$

Identification and implementation of a treatment that not only addresses the physical manifestation of pain, but addresses potential contributing causes is needed. The purpose of this case report is to present two instances of competitive athletes diagnosed with MTSS, who were treated successfully with MYK. This study was approved by the Institutional Review Board of University of Idaho following the Helsinki Declaration. All participants signed an informed consent prior to their inclusion.

\section{PATIENT INFORMATION}

\section{Patient One}

A nineteen-year-old male club rugby athlete complaining of bilateral shin pain reported to a musculoskeletal pain clinic. Previous history included MTSS seven years ago with no other lower extremity injuries or complaints. The prior bout of MTSS was of slow onset, aggravated only with repetitive activity (e.g., mile runs). Pain subsided when the patient refrained from physical activity and felt no need to seek any other form of treatment. Signs and symptoms of the new complaint included bilateral dull and diffused pain over the distal $2 / 3$ posteromedial aspect of the tibia during physical activity and upon palpation. The patient had been experiencing

Copyright (C) by Indiana State University All rights reserved. ISSN Online 2577-8188 pain for over a month, which progressed slowly from pain with running, to pain during and after activity, and finally to constant pain. Upon questioning, the patient reported a gradual increase in physical activity, which included running on turf and concrete. The patient's pain was measured by utilizing the Numeric Pain Rating Scale (NPRS). At initial evaluation, the patient reported his worst pain was $7 / 10$ bilaterally while running, best pain $0 / 10$ while seated, and current pain $1 / 10$ while walking. Function was measured by the Lower Extremity Functional Scale (LEFS) and disablement was assessed using the Disablement in the Physically Active (DPA) Scale. Initial scores were $47 / 80$ and $41 / 64$, on the LEFS and DPA scales, respectively.

\section{Patient Two}

A twenty-four year old female collegiate soccer athlete complaining of bilateral shin pain reported to her athletic trainer. The patient was otherwise healthy without current or past injuries to the lower extremity. The patient did not report a specific mechanism of injury; she stated running produced constant pain for the past four weeks with gradual worsening. The patient attempted to treat her symptoms with ice and stretching, reporting minimal to no improvement. The patient was initially evaluated mid-competition season with signs and symptoms that included aching and diffused pain along the distal $2 / 3$ posteromedial border of both tibia during weight bearing physical activities (i.e., running), and pain with palpation. The patient's pain was measured with the NPRS. At intake, her worst pain was $10 / 10$ bilaterally while running, best pain was $0 / 10$ at rest, and current pain $3 / 10$ while walking. Function was measured by the LEFS and disablement was assessed using the DPA scale. Initial scores were $59 / 80$ and $36 / 64$, on the LEFS and DPA scales, respectively.

\section{INTERVENTION}

Each patient was evaluated and treated at their respective clinics by a single clinician for the duration of their care. In both cases, an orthopedic examination was completed to determine 
diagnosis per established guidelines, ${ }^{4}$ as outlined in Table 1, and to rule out the presence of a stress fracture. Physical impairments may result from postural compensations and/or dysfunctions within the nervous system, therefore, the MYK postural analysis was used on each patient to assess and identify a primary nerve root dysfunction.9-10 The clinicians performed a static postural assessment by observing the patient's upper extremities, torso, and lower extremities in standing, seated, and prone positions. The clinicians used the posture assessment chart (Table 2) to connect postural imbalances to specific nerve root pathways innervating specific groups of muscles. The nerve pathway containing the greatest number of imbalances was identified as the primary dysfunctional nerve root at the time of assessment. Treatment was performed on the primary dysfunctional nerve root as determined through the postural assessment. ${ }^{9-10}$

Table 1. Signs and symptoms used for MTSS Diagnosis (Yates \& White, 2004)

\begin{tabular}{|l|l|}
\hline $\begin{array}{l}\text { Pain } \\
\text { History }\end{array}$ & $\begin{array}{l}\text { Pain with activity lasting hours } \\
\text { or days after activity. No } \\
\text { history of paraesthesia. }\end{array}$ \\
\hline Palpation & $\begin{array}{l}\text { Pain along the posteromedial } \\
\text { border of the tibia that was } \\
\text { spread out over an area of } 5 \\
\text { cm. }\end{array}$ \\
\hline $\begin{array}{l}\text { Diffuse tenderness over the } \\
\text { distal } 2 / 3 \text { posteromedial } \\
\text { border of tibia. }\end{array}$ \\
\hline
\end{tabular}

At intake, both cases' postural assessments indicated the S1 nerve root as the primary dysfunction due to it having the highest number of associated imbalanced postures. The administration of one treatment took approximately ten minutes. Treatment included manual stimulation of each muscle innervated by the S1 nerve root, applied bilaterally with alternating patterns of 4-10 passive movement repetitions immediately followed by $4-10$ active repetitions. In theory, the passive motions (Figure 1) are performed to clear muscle memory,

Copyright (C) by Indiana State University All rights reserved. ISSN Online 2577-8188 followed by active movements (Figure 2) to reestablish proper neuromuscular firing patterns. 9 Stimulation was applied during the passive and active muscle lengthening motions by using light or deep compressions, glides, or cross-friction. The combination of simultaneous movement and tactile feedback stimulates several ascending sensory tracts and improves communication between the CNS and the muscles innervated by the corresponding nerve root.

During each visit, both patients received a treatment session that consisted of two S1 treatment bouts. After each treatment bout, the patients walked for two minutes to allow the CNS to interpret and adjust to the feedback received during treatment. A second S1 treatment was administered immediately following the twominute walk. The session ended with a second twominute walk. This treatment protocol was used at subsequent visits. Discharge criteria was met after patients received a total of twelve MYK S1 treatments completed in six sessions over two weeks. Patients continued their sporting activities while undergoing MYK treatments and through the 15-day follow-up. During this time, both patients refrained from additional therapy.

\section{OUTCOME MEASURES}

The MYK posture analysis chart (Table 2) was utilized to assess and log each patient's posture. Additionally, patient reported outcomes measures collected that included the NPRS, the LEFS, the DPA scale, and the Global Rating of Change ( $G R \circ C$ ) scales. When a minimal amount of change needed to indicate importance to the clinician and patient, also known as the minimal clinical important difference (MCID) achieved, it was noted in Table 3. The NPRS is an 11-point scale, by which a score of zero indicates no pain and ten represents the worst pain imaginable, as perceived by the patient. $A$ change in two points on the NPR scale indicates an MCID. ${ }^{15}$ The LEFS is a 20-item questionnaire used to assess a person's ability to perform activities of daily living. Each item is scored by the patient; a score of 4 indicates no difficulty with the listed task while a

Clinical Practice in Athletic Training Volume 3 - Issue 3 - November 2020 
Table 2. The MyoKinesthetic ${ }^{\text {TM }}$ System Postural Assessment Chart (Uriarte, 2010) POSTURE CHART

\begin{tabular}{|c|c|c|c|}
\hline HEAD & & LUMBAR SPINE & \\
\hline Flexed & $-(\mathrm{Cl}-\mathrm{T} 1)$ & Flexed & - (L1 -L5) \\
\hline Extended & $-(\mathrm{C} 1-\mathrm{C} 3)$ & Extended & - (L1-L2) \\
\hline Rotated & $-(\mathrm{Cl}-\mathrm{T} 1)$ & Rotated & - (L1-L5) \\
\hline Laterally Flexed & $-(\mathrm{C} 1-\mathrm{T} 1)$ & Laterally Flexed & - (L1 -L2) \\
\hline SCAPULA & & HIP & \\
\hline Elevated & $-(\mathrm{C} 3-\mathrm{C} 4)$ & Flexed/Ant Rot & - (L5-S1) \\
\hline Depressed & $-(\mathrm{C} 3-\mathrm{C} 5)$ & Extended/Post Rot & - (LI -L5) \\
\hline Protracted (AB) & $-(\mathrm{C} 3-\mathrm{C} 5)$ & Abducted & - (L2-L3) \\
\hline Retracted (AD) & $-(C 5-C 8)$ & Adducted & - (L4-L5) \\
\hline Upward Rotated & $-(\mathrm{C} 3-\mathrm{C} 8)$ & Laterally Rotated & - (L2-S1) \\
\hline Downward Rotated & $-(\mathrm{C} 3-\mathrm{C} 7)$ & Medially Rotated & - (L5-S1) \\
\hline SHOULDER & & KNEE & \\
\hline Flexed & $-(\mathrm{C} 5-\mathrm{C} 8)$ & Flexed & - (L3-L4) \\
\hline Extended & $-(\mathrm{C} 5-\mathrm{C} 8)$ & Extended & - (S1) \\
\hline Depressed (AB) & $-(\mathrm{C} 5-\mathrm{C} 8)$ & Externally Rotated & $-(L 2-L 3, S 1)$ \\
\hline Elevated (ADD) & $-(C 5-C 6)$ & Internally Rotated & - (S1) \\
\hline Medially Rotated & $-(\mathrm{C} 5-\mathrm{C} 6)$ & & \\
\hline Laterally Rotated & $-(\mathrm{C} 5-\mathrm{C} 8)$ & & \\
\hline ELBOW & & ANKLE & \\
\hline Flexed & $-(\mathrm{C} 7-\mathrm{C} 8)$ & Plantar Flexed & - (L4) \\
\hline \multirow[t]{2}{*}{ Extended } & $-(C 5-C 7)$ & Dorsiflexed & - (S1-S2) \\
\hline & & Everted & - (L4) \\
\hline FOREARM & & Pronated & - (L4) \\
\hline Supinated & $-(\mathrm{C6}-\mathrm{T} 1)$ & Inverted & (L5-S1) \\
\hline Pronated & $-(\mathrm{C} 5-\mathrm{C} 6)$ & Supinated & (L5-S1) \\
\hline WRIST & & BIG TOE & \\
\hline Flexed & $-(\mathrm{C6}-\mathrm{C} 8)$ & Flexed & - (L5) \\
\hline Extended & $-(\mathrm{C} 5-\mathrm{T} 1)$ & Extended & $-(S 1-S 2)$ \\
\hline Radial Deviated & $-(C 7-C 8)$ & Abducted/Varus & $-(S 1-S 2)$ \\
\hline Ulnar Deviated & (C6-C7) & Adducted/Valgus & (L5-S1) \\
\hline THUMB & & TOES & \\
\hline Flexed & $-(C 7-T 1)$ & Flexed & - (L5) \\
\hline Extended & - (C6-T1) & Extended & $(\mathrm{S} 1-\mathrm{S} 2)$ \\
\hline Abducted & - (C8-T1) & & \\
\hline Adducted & $-(\mathrm{C} 6-\mathrm{T} 1)$ & & \\
\hline \multicolumn{4}{|l|}{ FINGER } \\
\hline Flexed & - (C6-T1) & & \\
\hline Extended & - (C7-T1) & & \\
\hline Abducted & $-(C 8-T 1)$ & & \\
\hline Adducted & $-(C 8-T 1)$ & & \\
\hline
\end{tabular}

Posture Chart, pg. 146, 1998, with permission from Elsevier ." 

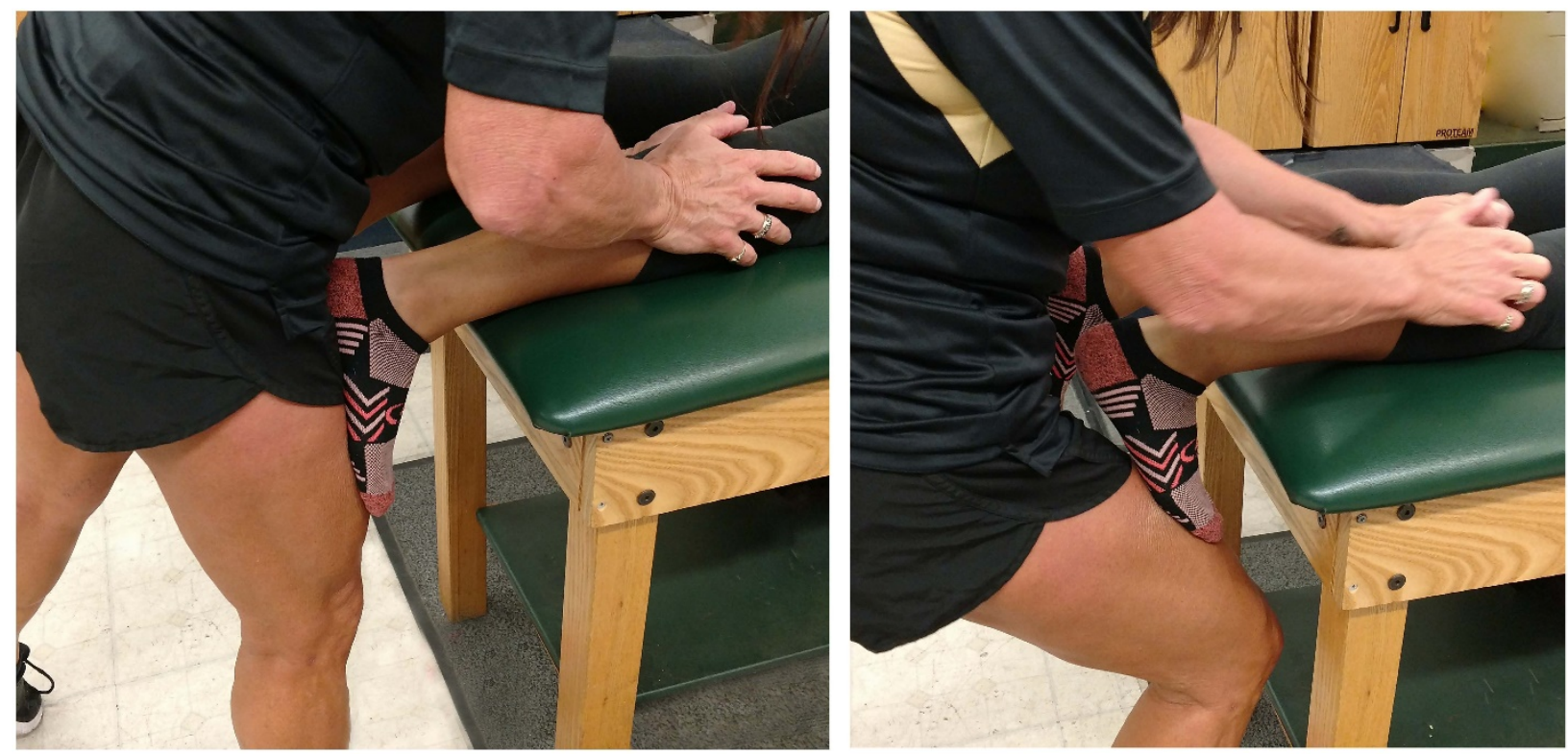

Figure 1: Start and End Positions for Passive Dorsiflexion
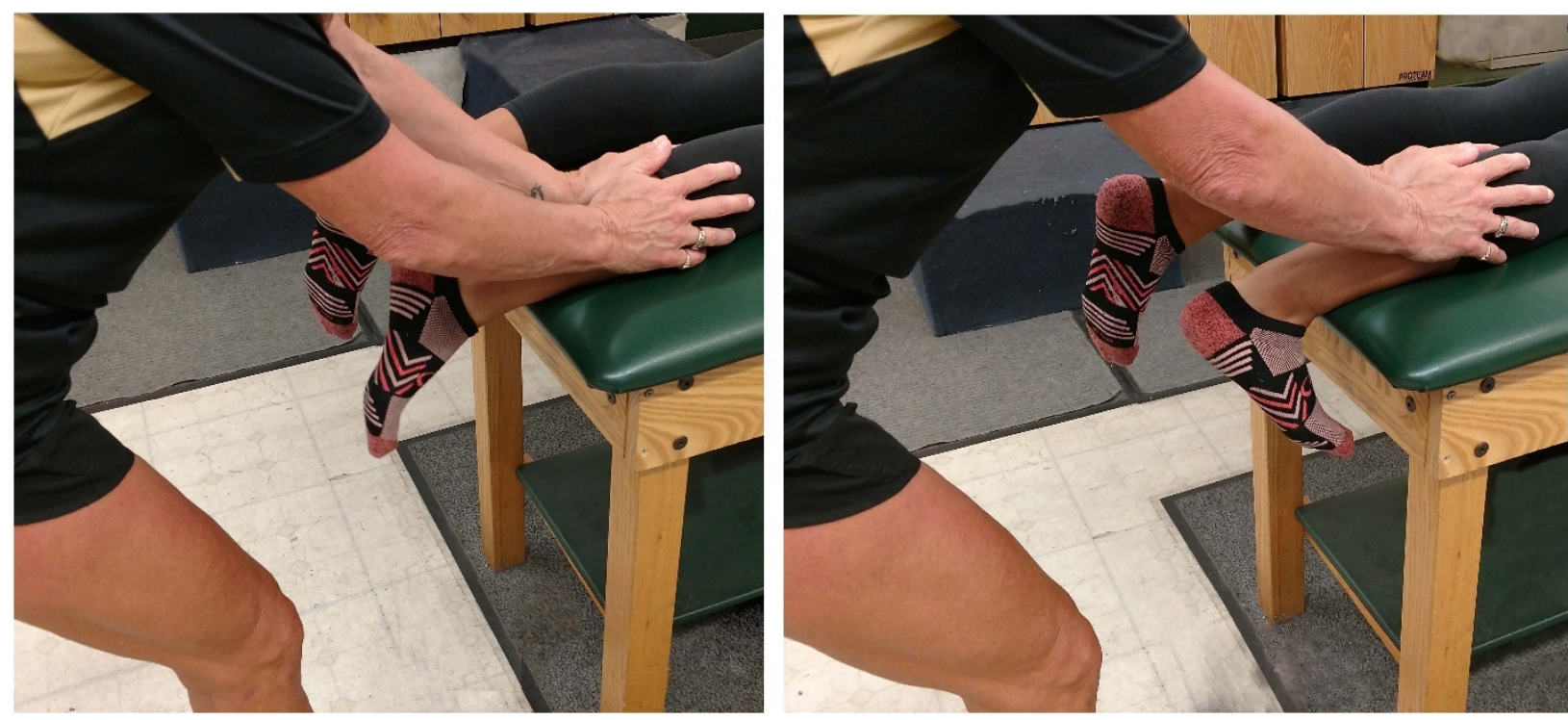

Figure 2: Start and End Positions for Active Dorsiflexion

score of 0 identifies a task that is impaired. An MCID on the LEFS is an increase of nine points. 16 The DPS scale is a 16-item questionnaire measuring impairments, functional limitations, disability and quality of life. A score $\leq 23$ is expected in healthy individuals. An established MCID on the DPA scale of nine for acute injuries and six for persistent injuries is the standard used to indicate meaningful change. ${ }^{17}$ The GRoC is a visual 11 -point scale used to quantify a patient's perceived progress over time (e.g., improvements, digressions). An MCID for the GRoC is an increase of two points. ${ }^{18}$

Outcomes were collected at regular intervals, as outlined in Table 3, and patients were considered for discharge when meeting the following criteria:

- NPRS $\leq 2$ average of best, worst, current, forty-eight hours after last treatment

- $\quad$ LEFS $\geq 70$ 
- DPA scale $\leq 23$ within the last forty-eight hours

- GroC $\geq 4$ from intake to twenty-four hours after final treatment

\section{RESULTS}

\section{Patient One}

After the first week of treatment (three treatment sessions), the patient achieved MCID for the NPRS, LEFS, DPA Scale, and reported a GRoC score of 3/5 (Table 3). Treatment continued for an additional week (three treatment sessions), until the patient experienced resolution of pain and met discharge criteria. Minimal clinical important differences were achieved for all NRS, LEFS, and DPA scale scores taken between intake and discharge, and a one-point increase on the GRoC at the time of discharge. At the fifteen-day follow-up, the patient remained pain free and continued to report improvements in function while remaining physically active. The patient reported no pain, no dysfunction, and a GRoC of five at six-month follow-up. Table 3 contains initial, discharge and fifteen-day follow-up results of the postural assessment and how it changed over the course of treatment.

\section{Patient Two}

After the first week of treatment (three treatment sessions), the patient improved scores for the NPRS, LEFS, and DPA Scale. Minimal clinically important difference scores were achieved for both the NPRS and DPA scale, and an initial GRoC score of $3 / 5$ was reported (Table 3). Treatment continued for an additional week (three treatment sessions), until the patient's symptoms improved and discharge criteria were met. Minimal clinical important differences were achieved for all outcome measures between intake and discharge, and a one-point increase on the GRoC at the time of discharge. At the fifteen-day follow-up the patient continued to experience decreases in pain and reported improvement in function while remaining physically active and participating in soccer activities. At the six-month follow-up, the

Copyright (C) by Indiana State University All rights reserved. ISSN Online 2577-8188 patient reported no pain, no dysfunction, and a GRoC of five. Table 3 includes a summary of outcome measures across all time points, and postural assessment results for initial, discharge and fifteen-day follow-up.

\section{DISCUSSION}

In this case report, MYK was effective in reducing pain and restoring function in an accelerated time frame for two athletes suffering from MTSS, without being removed from activity. Clinically significant results were achieved in both cases as measured by the NPRS, DPA Scale and LEFS after treating exclusively with this technique. Minimal clinically important differences were achieved in both cases across all collected outcome measures within three treatment sessions and again at discharge. Minimal clinically important differences were achieved in both cases across all collected outcome measures within three treatment sessions and again at discharge. Patient 1 remained pain free and self-reported excellent outcome measures at fifteen-day and six-month follow-ups. Patient 2 was fully functional with soccer activities and met discharge criteria with an average NPRS score of $1 / 10$ at discharge. At the fifteen-day follow-up her average NPRS score was $0.33 / 10$, the patient reported her worst pain $(1 / 10)$ was re-produced only during particularly vigorous soccer activity. At the six-month follow-up, patient two reported being pain free and fully functional.

Currently, clinicians have various options to treat patients with MTSS. The evidence supporting traditional treatments (e.g., rest, ice, stretching, and strengthening exercises) is not promising, as pain and dysfunction recur with activity. 2,19 The use of limited activity in combination with traditional treatments and a gradual return to play progression can take up to one-hundred days for the patient to report resolution of symptoms. ${ }^{19}$ Rest alone can take up to six weeks until a patient is pain free. ${ }^{20}$ In this case report, two patients experienced significant improvement of symptoms in two weeks without activity limitations, and maintained long-term results. 
Table 3. Patient Outcomes

\begin{tabular}{|c|c|c|c|c|c|}
\hline \multicolumn{6}{|l|}{ Patient One } \\
\hline Outcome & Intake & 1 week & Discharge & $\begin{array}{l}15 \text { day } \\
\text { Follow-up }\end{array}$ & $\begin{array}{l}6 \text { month } \\
\text { Follow-up }\end{array}$ \\
\hline NPRS Ave.: & 2.66 & 1 & 0 & 0 & 0 \\
\hline Worse & 7 & 3 & 0 & 0 & 0 \\
\hline Current & 1 & 0 & 0 & 0 & 0 \\
\hline Best & 0 & 0 & 0 & 0 & 0 \\
\hline DPA Scale & 41 & 16 & 2 & 0 & 0 \\
\hline LEFS & 47 & 64 & 73 & 80 & 80 \\
\hline GRoC & - & 3 & 4 & 5 & 5 \\
\hline MYK Posture & S1 & - & C5 & C6 & - \\
\hline \multicolumn{6}{|l|}{ Patient Two } \\
\hline Outcome & Intake & 1 week & Discharge & $\begin{array}{l}15 \text { day } \\
\text { follow up }\end{array}$ & $\begin{array}{l}6 \text { month } \\
\text { follow up }\end{array}$ \\
\hline NPRS Ave.: & 4.33 & 1.66 & 1 & 0.33 & 0 \\
\hline Worse & 10 & 3 & 3 & 1 & 0 \\
\hline Current & 3 & 2 & 0 & 0 & 0 \\
\hline Best & 0 & 0 & 0 & 0 & 0 \\
\hline DPA Scale & 36 & 9 & 6 & 0 & 0 \\
\hline LEFS & 59 & 66 & 77 & 80 & 80 \\
\hline GRoC & - & 3 & 4 & 4 & 5 \\
\hline MYK Posture & S1 & - & $\mathrm{C} 7 / \mathrm{C} 8$ & $\mathrm{C} 7 / \mathrm{C} 8$ & - \\
\hline
\end{tabular}

NPRS- Numeric Pain Rating Scale; DPA scale- Disablement in the Physically Active Scale; LEFS- Lower Extremity Functional Scale; GroC- Global Rating of Change; MYK-

Myokinesthetic

*= Minimally Clinically Important Difference

A previous history of MTSS has been linked to high recurrence rates. ${ }^{2,21-22}$ Biomechanical, as well as structural abnormalities, are associated with lower extremity injuries causing dysfunctions along the kinetic chain. ${ }^{20,} 23-25$ A visual observation of standing postures can help detect anomalies such as genu varum, pes planus, hyperpronated foot, increased forefoot and rear foot arch, which has been associated as intrinsic risk factors in patients with MTSS. $20,25-27$ The changes brought about by the MYK treatment may have reduced intrinsic risk factors as they relate to posture and movement, resulting in long-term results.

The patients experienced clinically significant improvements across all measures (i.e., selfreported pain, disablement, and function) meeting discharge criteria after two weeks of treatment; compared to rest alone that may take up to six weeks. ${ }^{20} \mathrm{At}$ the end of the two-week treatment

Copyright (C) by Indiana State University All rights reserved. ISSN Online 2577-8188 period, both patients experienced changes in previously dysfunctional postures. Within the S1 nerve root, patient 1 corrected two dysfunctional postures and patient 2 corrected four. Although patient 1 experienced fewer changes in posture, his pain was still eliminated. In patient 2 , some postures within the $S 1$ nerve root remained present at discharge, however enough postures were corrected to contribute to a combined positive effect on the system resulting in decreased pain and increased function. Theoretically, the summation of positional variations could have reduced stress loads in the lower kinetic chain. Additionally, changes may continue during activity as the CNS configures afferent and efferent communication, correcting unbalanced patterns until allostasis has been achieved. Corrected patterns may continue to have a positive impact on symptoms as the body 
continues to move, even if treatments are no longer administered.

Several limitations to the study warrant discussion. Internal validity may have been compromised as patient 1 reported a self-bias. The patient stated that he did not believe the treatment would resolve his condition, which might have resulted in delayed healing and extended treatment time. External validity is low since these two patients may not be generalized to larger populations. Further investigation into the effects of MYK with rest on MTSS is warranted. A larger-scale trial is needed to explore how postural changes affect the long- and short-term effects of MTSS.

\section{CLINICAL BOTTOM LINE}

The exact etiologies of MTSS are unknown, but risk factors associated with this syndrome are numerous. Conservative treatments focus on the local area of pain and do not address intrinsic risk factors. The MyoKinesthetic System, in comparison to traditional treatments, addresses postural risk factors to help prevent and/or decrease the signs and symptoms associated with the syndrome. As the number of risk factors decreased in both patients so did pain intensity. The results of this case report provide evidence of the short and long-term effects of MYK to decrease pain in two patients presenting with MTSS while remaining physically active. Through this case report we found that posture indeed may be an outward expression of the nervous system, encouraging clinicians to consider addressing structural compensations. A full-scale investigation of MYK is needed to determine its ability to effectively treat and address postural risk factors that lead to MTSS.

\section{REFERENCES}

1. Brewer RB, Gregory AM. Chronic lower leg pain in athletes: a guide for the differential diagnosis, evaluation, and treatment. Sport Health. 2012; 4(2):121-127. https://doi.org/10.1177\%2F19417381114 26115.

2. Schulze C, Finze S, Bader R, Lison A. Treatment

Copyright (C) by Indiana State University All rights reserved. ISSN Online 2577-8188 of medial tibial stress syndrome according to the fascial distortion model: a prospective case control study. Sci World J. 2014. https://doi.org/10.1155/2014/790626.

3. Hubbard TJ, Mullis Carpenter E, Cordova ML. Contributing factors to medial tibial stress syndrome: a prospective investigation. Med Sci Sport Exer. 2009; 41(3):490-496. https://doi.org/10.1249/MSS.0b013e3181 8b98e6.

4. Yates $B$, White $S$. The incidence and risk factors in the development of medial tibial stress syndrome among naval recruits. Am J Sport Med. 2004; 32(3):772-780. https://doi.org/10.1177/0095399703258 776.

5. Burrus MT, Werner BC, Starman JS, et al. Chronic leg pain in athletes. Am J Sport Med. 2015; 43(6): 1538-1547. https://doi.org/10.1177/0363546514545 859.

6. Moen MH, Bongers T, Bakker EW, et.al. Risk factors and prognostic indicators for medial tibial stress syndrome. Scand J Med Sci Sport. 2012;

https://doi.org/10.1111/i.160022:34-39. 0838.2010.01144.x.

7. Cook G. Movement: Functional Movement Systems: Screening Assessment, and Corrective Strategies. Santa Cruz, CA: On Target Publications; 2010.

8. Total Motion Release. Research \& Evidence 2018. https://tmrseminars.com/researchevidence. Accessed November 19, 2018.

9. Uriarte M. MyoKinesthetic system: lower body lumbar and sacral plexus. 4th ed. 2010.

10. Brody K, Baker RT, Nasypany A, May J. The MyoKinesthetic system, part I: a clinical assessment and matching treatment intervention. Int J Athl Ther Train. 2015; 20(4):5-9. https://doi.org/10.1123/ijatt.2014-0131.

11. Brody K, Nasypany A, Baker RT, May J. Analysis of patient outcomes using the MyoKinesthetic System for the treatment of low back pain: a case series. J Chiropr Med. 2017; 16(2):111-121. https://doi.org/10.1016/i.jcm.2017.01.002

12. Hansen-Honeycutt J, Nasypany, A, Baker, RT. Treatment utilizing a Muscle Energy Technique and the MyoKinesthetic System on patients 
with a diagnosed disc injury. Int $J$ Athl Ther Train. 2016; 22(4):6-12. https://doi.org/10.1123/ijatt.2016-0013

13. Stevenson VF, Baker RT, May J, Nasypany A. Using the MyoKinesthetic System to treat bilateral chronic knee pain: a case study. $J$ Chiropr Med. 2016; 15(4):294-298. https://doi.org/10.1016/i.jem.2016.07.002

14. Martinez RE, Lopez EB, Cox RW, et al. Exploring treatment of medial tibial stress syndrome via posture and the MyoKinesthetic system. J Bodyw Mov Ther. 2020; 24(1):8287. https://doi.org/10.1016/i.jbmt.2019.06.00 4.

15. Krebs EE, Carey SC, Weinberger M. Accuracy of the pain numeric rating scale as a screening test in primary care. J Gen Intern Med. 2007; 22(10): $1453-1458$. https://doi.org/10.1007/s11606-0070321-2.

16. Yeung TSM, Wessel J, Stratford $P$, Macdermid J. Reliability, validity, and responsiveness of the lower extremity functional scale for inpatients of an orthopaedic rehabilitation ward. J Orthop Sports Phys Ther. 2009; 39(6):468-477. https://doi.org/10.2519/iospt.2009.2971.

17. Vela LI, Denegar CR. The disablement in the physically active scale, part II: the psychometric properties of an outcomes scale for musculoskeletal injuries. J Athl Train. 2010; 45(6):630-641.

https://doi.org/10.4085/1062-605045.6.630.

18. Kamper SJ, Maher CG, Mackay G. Global rating of change scales: $A$ review of strengths and weaknesses and considerations for design. J Man Manip Ther. 2009; 17(3):163170.

https://doi.org/10.1179/imt.2009.17.3.16 3.

19. Moen MH, Holtslag L, Bakker E. The treatment of medial tibial stress syndrome in athletes; a randomized clinical trial. Sport Med Arthrose Rehabil Ther Technol. 2012; 4:12. https://doi.org/10.1 186/1758-2555-4-12.

20. Galbraith RM, Lavallee ME. Medial tibial stress syndrome: conservative treatment options. Curr Rev Musculoskelet Med. 2009; 2:127-133. https://doi.org/10.1007/s12178-0099055-6.

21. Newman P, Witchalls J, Waddington G, Adams R. Risk factors associated with medial tibial stress syndrome in runners: A systematic review and meta-analysis. Open Access $J$ Sports Med. 2012; (4):229-241. https://doi.org/10.2147/OAJSM.S39331.

22. Reinking MF. Exercise related leg pain (ERLP): a review of the literature. N Am J Sport Phy Ther. 2007; 2(3):170-180.

23. Cosca DD, Navazio F. Common problems in endurance athletes. Am Fam Physician. 2007; 76(2):237-244.

24. Neal BS, Griffiths IB, Dowling GJ, et al. Foot posture as a risk for lower limb overuse injury: A systematic review and meta-analysis. J Foot Ankle Res. 2014; 7(55). https://doi.org/10.1186/s13047-0140055-4.

25. Reinking MF, Austin TM, Hayes AM. Exercise related leg pain in collegiate cross-country athletes: extrinsic and in intrinsic risk factors. J Orthop Sport Phy Ther. 2007; 37(11):670678.

https://doi.org/10.2519/iospt.2007.2534.

26. Bennett JE, Reinking MF, Pluemer $B$, et al. Factors contributing to the development of medial stress syndrome in high school runner. J Orthop Sport Phy Ther. 2001; 31(9):504510. https://doi.org/10.2519/iospt.2001.31.9.5 04.

27. Sommer HM, Vallentyne SW. Effect of foot posture on the incidence of medial tibial stress syndrome. Med Sci Sports Exerc. 1995; 27(6):800-804. 